Thorax, 1979, 34, 51-56

\title{
Bronchodilatation and the site of airway resistance in severe chronic bronchitis
}

\author{
N J DOUGLAS, I DAVIDSON, M F SUDLOW, AND D C FLENLEY \\ From the Department of Medicine, University of Edinburgh, The Royal Infirmary, Edinburgh, UK
}

\begin{abstract}
Twenty-one patients with severe chronic bronchitis and emphysema $\left(\mathrm{FEV}_{1}<11\right)$ inhaled $80 \mu \mathrm{g}$ of the atropine-like agent ipratropium or placebo in a double-blind study and three hours later inhaled $200 \mu \mathrm{g}$ salbutamol. After $80 \mu \mathrm{g}$ ipratropium, mean $\mathrm{FEV}_{1}$ was significantly greater than after $200 \mu \mathrm{g}$ salbutamol ( $<<0.025)$, but the difference was only $40 \mathrm{ml}$ and the clinical significance of this difference is unproved. There was no correlation between the patient's response to ipratropium and the response to salbutamol. When salbutamol was administered three hours after ipratropium, the $\mathrm{FEV}_{1}$ rose to higher levels than after either agent alone $(P<0 \cdot 01)$. Studies breathing $80 \%$ helium $/ 20 \%$ oxygen suggest that ipratropium dilates both large and small airways. There was no correlation between the response to helium/oxygen and the response to either bronchodilator.

The results suggest that in severe chronic bronchitis and emphysema ipratropium is at least as effective as salbutamol, and that such patients should have reversibility studies with salbutamol alone, ipratropium alone, and after both agents together. The combination of ipratropium and salbutamol may be clinically useful.
\end{abstract}

Atropine inhalation has been used to treat obstructive airways disease in the West since the early nineteenth century, when the smoking of various Datura species was introduced from India (Christie, 1811). With the advent of sympathomimetic drugs, atropine fell into disuse for the treatment of asthma and bronchitis, but recently interest in its role as a bronchodilator has been revived (Herxheimer, 1959; Altounyan, 1964; Yu et al, 1972). Atropine is thought to act by inhibiting the bronchomotor tone, which depends on efferent fibres in the vagus (Cabezas et al, 1971).

Ipratropium bromide (Atrovent, SCH 1000, Boehringer Ingelheim) is an atropine-like drug available in a metered dose inhaler. In the past few years it has been evaluated both in asthma and chronic bronchitis (Poppius and Salorinne, 1973; Petrie and Palmer, 1975; Postgraduate Medical Journal, 1975; Storms et al, 1975). In chronic bronchitics it is as effective as salbutamol in increasing FEV 1 (Petrie and Palmer, 1975) and peak expiratory flow rate (Poppius and Salorinne, 1973), and possibly even more effective than salbutamol in increasing specific airways conductance (sGaw) (Poppius and Salorinne, 1973). High doses of ipratropium can be given by aerosol, thus pro- ducing inhibition of vagally mediated bronchomotor tone without the systemic side effects of atropine, for ipratropium by aerosol yields very low plasma concentrations of the drug (Postgraduate Medical Journal, 1975).

We have used ipratropium to assess the importance of vagally mediated bronchomotor tone in patients with severe chronic bronchitis and emphysema. Despite the hypertrophied bronchial muscle found in such patients (Hossain and Heard, 1970), we thought that reduction of tone in this muscle would have little effect on the resistance to airflow in their bronchial tree, which we presumed to be extensively deranged, with loss and permanent obstruction of many airways, as a result of their long-standing disease (Thurlbeck et al, 1970).

\section{Methods}

We studied 17 men and four women, aged 49-71 (mean 65) who suffered from chronic obstructive bronchitis (Medical Research Council, 1965). All

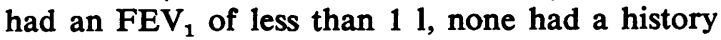
of asthma, none had a blood eosinophilia greater than $0.2 \times 10^{\circ} / 1$, and no patient was taking oral 
steroids. Eleven were cigarette smokers and 10 ex-smokers. All were severely dyspnoeic on minimal exertion, and none was at work. No patient had had a chest infection within six weeks of the study, each patient's $\mathrm{FEV}_{1}$ had been stable within 0.151 over the past six months, and in each the initial $\mathrm{FEV}_{1}$ on the days of the tests was within 0.151 of their usual outpatient value. Their arterial $\mathrm{PO}_{2}$, when breathing air, varied from $5 \cdot 1-11 \cdot 1 \mathrm{kPa}$ $(38-83 \mathrm{mmHg})$, mean $8.4 \mathrm{kPa}(63 \mathrm{mmHg})$, arterial $\mathrm{PCO}_{2} 5 \cdot 1-8 \cdot 3 \mathrm{kPa}(38-62 \mathrm{mmHg})$, mean $6 \cdot 7 \mathrm{kPa}$ (50 $\mathrm{mmHg}$ ), and arterial $\mathrm{H}+$ concentration $36-46$ $\mathrm{nmol} / \mathrm{l}$ (pH 7·34-7.44), mean $39 \mathrm{nmol} / \mathrm{l}(\mathrm{pH} \mathrm{7 \cdot 41)}$, indicating compensated respiratory acidosis. All bronchodilator treatment was stopped for 12 hours before the studies. The study was approved by the hospital ethical committee, and each patient gave informed consent to the studies.

In a preliminary study $\mathrm{FEV}_{1}$ and $\mathrm{FVC}$ were measured in four of the patients before and 15, $30,45,60,75,90,120,180$, and 240 minutes after inhaling $400 \mu \mathrm{g}$ salbutamol. A cumulative salbutamol dose-response study was performed on the same four patients in which each patient inhaled salbutamol $100 \mu \mathrm{g}$ at time $0,100 \mu \mathrm{g}$ at $30 \mathrm{~min}$, $200 \mu \mathrm{g}$ at $60 \mathrm{~min}, 400 \mu \mathrm{g}$ at $90 \mathrm{~min}$, and finally $80 \mu \mathrm{g}$ ipratropium at $120 \mathrm{~min}, \mathrm{FEV}_{1}$ and FVC being measured at $0,30,60,90,120$, and 180 minutes.

In a double-blind crossover study each patient received either $80 \mu \mathrm{g}$ (four puffs) of ipratropium bromide, or four puffs of a placebo, from a metered dose inhaler at the same time of day on two consecutive days. Immediately before the inhalation, and at 90 and 180 minutes thereafter, we recorded expiratory volume and flow rate (Ohio 840 spirometer) during the FVC manoeuvre. We measured $\mathrm{FEV}_{1}, \mathrm{FVC}$, and the flow rate at $50 \%$ vital capacity $\left(V \max _{50}\right)$ on three occasions when breathing air, and also after three vital capacity breaths of an $80 \%$ helium and $20 \%$ oxygen mixture $\left(\mathrm{He} / \mathrm{O}_{2}\right)$, recording the highest values observed when breathing each gas.

One hundred and eighty minutes after inhaling either ipratropium or the placebo each patient inhaled $200 \mu \mathrm{g}$ of salbutamol from a metered dose inhaler (two puffs), FEV 1 and FVC being measured again 15 and 30 minutes later. We also noted pulse rate and side effects before and after each inhalation. This experimental design allows comparison of measurements after ipratropium alone, after salbutamol alone, after placebo alone, and after the sequential administration of ipratropium and salbutamol.

In six patients (two men and four women) lung volumes and sGaw were measured before and 90 minutes after inhaling $80 \mu \mathrm{g}$ ipratropium bromide, $\stackrel{\overrightarrow{\bar{N}}}{\stackrel{D}{\circ}}$ and also after four puffs of placebo, using a pressure compensated flow body plethysmograph (Stanescu et al, 1972).

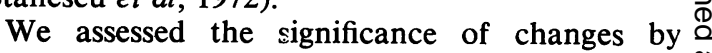
paired $t$ test.

\section{Results}

Studies in four of the patients have suggested that the maximal effect both on $\mathrm{FEV}_{1}$ and FVC oc- $\vec{x}$ curred within 15 minutes (fig 1) and lasted for $\underset{\perp}{\dot{\omega}}$ about two hours after inhalation of $400 \mu \mathrm{g}$ sal- $\overrightarrow{\dot{c}}$ butamol alone. Thus the change in $\mathrm{FEV}_{1}$ and $\stackrel{\mathrm{G}}{\rightarrow}$ FVC measured in the cumulative dose-response 을 study can be taken to reflect total inhaled dosages of salbutamol of $100,200,400$, and $800 \mu \mathrm{g}$ (fig 2), T and there would have been no appreciable reduc- $\frac{\mathbb{O}}{\mathrm{O}}$ tion of response to the inhaled salbutamol by 180 minutes when measurements were made after ipratropium. There was no change in $\mathrm{FEV}_{1}$ be- $\vec{\varphi}$
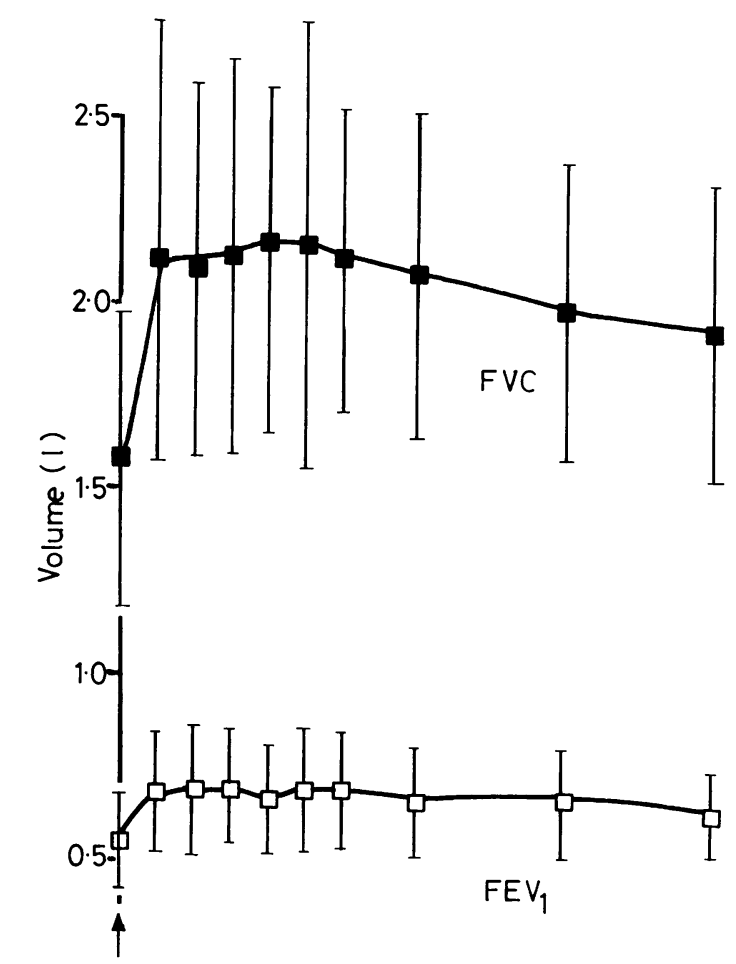

Subutamol

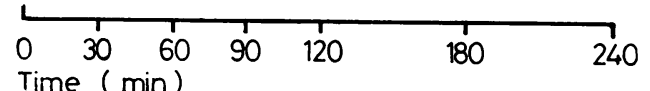

Fig 1 Time course of FEV and FVC after inhaling $200 \mu \mathrm{g}$ salbutamol-mean $\pm S D$ for four patients. 


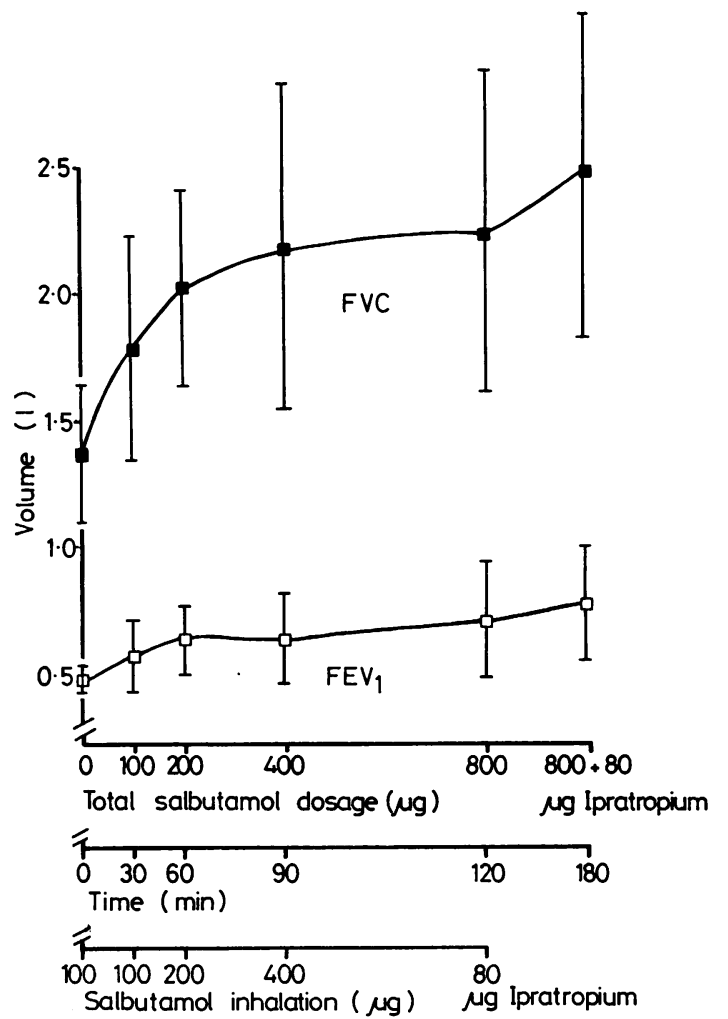

Fig 2 Cumulative dose response studies in four patients with mean $\pm S D$ for $F E V_{1}$ and $F V C$.

tween the 200 and $400 \mu \mathrm{g}$ dose, but there was a slight rise at $800 \mu \mathrm{g}$. FVC rose gradually up to the $800 \mu \mathrm{g}$ dosage level. In all four patients the addition of $80 \mu \mathrm{g}$ of ipratropium resulted in a higher FEV 1 and FVC than after $800 \mu \mathrm{g}$ salbutamol alone.

In the main study (fig 3) 180 minutes after the inhalation of ipratropium the $\mathrm{FEV}_{1}$ had risen on average from 0.58 to $0.731(\mathrm{P}<0.001)$ and FVC had risen from 1.45 to $1.931(\mathrm{P}<0.001)$. Salbutamol also produced a significant rise in mean $\mathrm{FEV}_{1}$ from 0.58 to $0.691(\mathrm{P}<0.001)$ and in FVC from 1.50 to $1.841(\mathrm{P}<0.001)$, the maximal rise being seen 30 minutes after inhalation. After ipratropium the $\mathrm{FEV}_{1}$ was significantly greater than after salbutamol $(P<0.025)$, but there was no significant difference in FVC $(0.20>\mathrm{P}>0.10)$. When salbutamol was inhaled 180 minutes after ipratropium both the $\mathrm{FEV}_{1}$ and FVC rose to significantly higher levels than after either agent alone ( $P<0.01$ ) (fig 3).

Nineteen of the 21 subjects reproduced their FVC breathing air and breathing $\mathrm{He} / \mathrm{O}_{2}$ to within

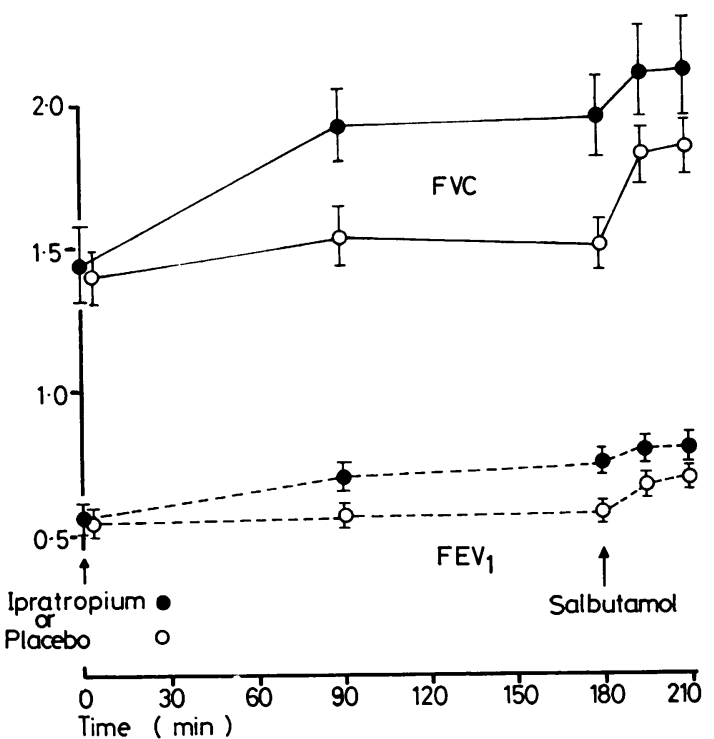

Fig 3 Effects of inhaling ipratropium or placebo aerosol followed by salbutamol on FEV ${ }_{1}$ and FVC. Mean values $\pm S E$ for the 21 patients are shown.

$100 \mathrm{ml}$ both in the control period and two hours after inhaling ipratropium. In the control period there was no difference between the mean flow rate at $50 \% \mathrm{VC}$ achieved breathing air (0.33 SD $0.18 \mathrm{lps})$ or breathing $\mathrm{He} / \mathrm{O}_{2}(0.33 \mathrm{SD} 0.19 \mathrm{lps})$ in these 19 patients. In 10 patients $V \max _{50}$ was greater, and in five smaller, when breathing $\mathrm{He} / \mathrm{O}_{2}$ as compared with breathing air, and in four there was no change (fig 4). Two hours after the inhalation of ipratropium $\mathbf{V} \max _{50}$ was significantly greater $(\mathrm{P}<0.01)$, both breathing air $(0.35 \mathrm{SD}$ $0.15 \mathrm{lps})$ and breathing $\mathrm{He} / \mathrm{O}_{2}(0.38 \mathrm{SD} 0.24 \mathrm{lps})$, but the difference between the flow rates breathing air and breathing $\mathrm{He} / \mathrm{O}_{2}$ was not significant $(P>0.3)$

In the six patients studied in the body plethysmograph sGaw rose from 0.35 to $0.50 \mathrm{sec}^{-1} \mathrm{kPa}^{-1}$ (0.035 to $\left.0.050 \mathrm{sec}^{-1} \mathrm{cmH}_{2} \mathrm{O}^{-1}\right)$ after ipratropium. A paired $t$ test carried out on the logarithm of sGaw values showed this rise in sGaw to be significant $(P<0.02)$. Ipratropium did not change the total lung capacity, but the residual volume fell from 3.76 (SD 0.82) 1 to 3.47 (SD 0.87) $1(P<0.02)$.

There was no significant change in pulse rate either after ipratropium (88 SD 3) as compared to placebo (91 SD 3) or after salbutamol (94 SD 3) as compared to placebo (91 SD 3) or after the combination of both agents (91 SD 4). No side effects were reported, although the dose of ipratropium given was twice that normally recom- 


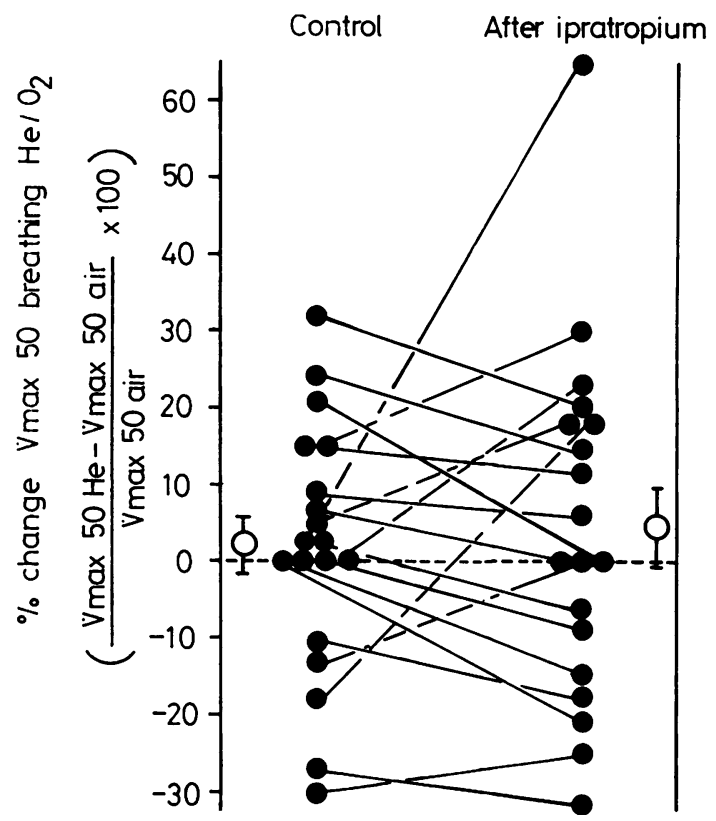

Fig 4 Effects of breathing $\mathrm{He} / \mathrm{O}_{2}$ on forced expiration before (control) and two hours after ipratropium inhalation. Individual values (๑) for percentage change in maximum flow at $50 \%$ vital capacity (calculated as shown) and mean $\pm S E$ are given.

mended by the manufacturers. Several patients disliked the bitter taste of ipratropium.

\section{Discussion}

The inhalation of ipratropium bromide produced a small but significant increase in both $\mathrm{FEV}_{1}$ $(26 \%)$ and FVC $(33 \%)$ in our patients with severe chronic obstructive airways disease, with a maximal effect at 180 minutes after the inhalation, extending previous observations on smaller numbers of less severely affected patients (Petrie and Palmer, 1975). Herxheimer (1959) found a small increase in FVC in a mixed group of both asthmatics and bronchitics after smoking a cigarette impregnated with atropine. Although the FVC rose after ipratropium inhalation in our severely bronchitic patients, their total lung capacity did not change, but their residual volume fell, indicating that the rise in FVC resulted from this fall in residual volume. In patients with chronic bronchitis and emphysema the residual volume is probably determined by closure of small airways. The fall in residual volume after ipratropium may result from an increase in the stability of these small airways, so that they then close at a $\stackrel{\overline{0}}{\stackrel{9}{+}}$ higher pleural pressure. This notion is consistent with the observation that methacholine (which has the opposite effect to atropine, increasing airway $\frac{\text { ? }}{7}$ tone) increases residual volume in normal subjects, $₫$ probably by reducing airway stability (Engel $e t$ al, \& 1976).

The ratio of $\mathrm{FEV}_{1}$ to $\mathrm{FVC}\left(\mathrm{FEV}_{1} / \mathrm{FVC}\right)$ is usually over $70 \%$ in health, and a fall in this $\vec{\omega}$ ratio is widely accepted as indicating airway obstruction. In asthmatics bronchodilatation with $\vec{x}$ salbutamol increases the $\mathrm{FEV}_{1} / \mathrm{FVC}$ ratio (Palmer $\omega$ and Diament, 1969). In our bronchitics ipratropium produced a proportionately greater rise is in FVC than in $\mathrm{FEV}_{1}$, so that the $\mathrm{FEV}_{1} / \mathrm{FVC} \overrightarrow{\mathrm{o}}$ ratio fell from $42 \%$ (SD 13\%) to $39 \%$ (SD 11\%) $(\mathrm{P}<0.05)$. This might have been taken to imply $\vec{T}$ an increase in airway obstruction, whereas our $\mathbb{C}$ direct measurements of sGaw show that the drug caused significant bronchodilatation. Salbutamol did not alter the $\mathrm{FEV}_{1} / \mathrm{FVC}$ ratio.

We found a greater rise in $\mathrm{FEV}_{1}$ after ipratropium in these patients with severe chronic bronchitis than after salbutamol. Petrie and Palmer (1975) did not find such a difference between these drugs, and Poppius and Salorinne (1973) found both drugs to have a similar effect on the peak expiratory flow rate. Our results may $\stackrel{\mathbb{Q}}{2}$ arise from studying patients with more severe $\overrightarrow{\overrightarrow{0}}$ disease, and also from our use of twice the dose of 3 ipratropium, but others (Postgraduate Medical Journal, 1975) have found that the response to ipratropium in mild bronchitis or in asthma was maximal with $40 \mu \mathrm{g}$ dose of ipratropium-half the dosage used in this trial.

This difference does not seem to be due to achieving poor $\beta_{2}$-sympathetic stimulation with $200 \mu \mathrm{g}$ salbutamol, as the cumulative dose response $ᄋ$ study (fig 2) suggests that the increase in $\mathrm{FEV}_{1}$ after $200 \mu \mathrm{g}$ was the greatest that could be $\frac{\rho}{2}$ achieved without the unpleasant effects and poten- $\rightarrow$ tial hazards experienced at $800 \mu \mathrm{g}$. It must be emphasised that although $\mathrm{FEV}_{1}$ after ipratropium $\mathrm{N}_{\mathcal{O}}$ was significantly higher than after salbutamol, the difference was only $40 \mathrm{ml}$, and the clinical signifi- O cance of this difference is dubious and remains to $\omega$ be proved. It can be said, however, that ipratropium is at least as effective as salbutamol in these patients.

So far as we are aware this is the first study to $\stackrel{?}{+}$ show that the combination of ipratropium and ${ }^{\circ}$ salbutamol produced a significantly greater bron- $\frac{O}{\mathbb{D}}$ chodilatation in patients with bronchitis than $\stackrel{\square}{\square}$ either agent alone. Other workers have noted that $\stackrel{\unrhd}{\Omega}$ such combination therapy has produced a slightly greater effect on $\mathrm{FEV}_{1}$ than either agent alone, 
but these differences were not significant (Petrie and Palmer, 1975; Baronti and Grieco, 1976). After both agents given in combination there was a $35 \%$ increase in $\mathrm{FEV}_{1}$ and a $45 \%$ increase in FVC. In the dose-response study (fig 2) the addition of $80 \mu \mathrm{g}$ ipratropium to $800 \mu \mathrm{g}$ salbutamol resulted in further bronchodilatation in all four subjects. The combined use of a beta-sympathetic stimulant and an atropinic agent by inhalation may prove valuable in clinical practice.

The change in $\mathrm{FEV}_{1}$ after salbutamol was not correlated with that in the same patient after ipratropium $(r=0.16)$, whereas Petrie and Palmer (1975) did find the two responses to be correlated significantly in a mixed group of patients with asthma and bronchitis. In patients with bronchitis the response of the individual patient should be assessed to both a beta-sympathomimetic bronchodilator and an atropinic agent, both separately and together.

A mixture of $80 \%$ helium and $20 \%$ oxygen $\left(\mathrm{He} / \mathrm{O}_{2}\right)$ has a density that is only $30 \%$ that of air but is $11 \%$ more viscous. The cross-sectional area of the bronchial tree greatly increases as the airways divide (Weibel, 1963), so that flow in the small airways may be slow and laminar, contrasting with the more rapid and disturbed flow in the trachea and major bronchi. As laminar flow depends on viscosity, if expiratory flow rates are determined by the resistance of small airways, breathing $\mathrm{He} / \mathrm{O}_{2}$ would cause a fall in $\mathrm{V} \max _{50}$, as seen in five of our patients (fig 4). Conversely, rapid and disturbed flow depends on the density of the gas in the bronchial tree, and therefore, if flow was limited by the resistance of large airways, flow rates would rise when breathing the $\mathrm{He} / \mathrm{O}_{2}$ mixture (Pedley et al, 1970). In normal subjects $\mathrm{V} \max _{50}$ breathing $\mathrm{He} / \mathrm{O}_{2}$ is $40-60 \%$ greater than breathing air (Despas et al, 1972; Benatar et al, 1975 ). In our patients $V \max _{50}$ rose on average only $2 \%$ when breathing $\mathrm{He} / \mathrm{O}_{2}$ (fig 4) compared with $11-13 \%$ increases previously found in groups of less severely disabled bronchitics (Despas et al, 1972; Wellman et al, 1976). We have studied (Kanbour et al, 1977) the washout of nitrogen by three vital capacity breaths of $\mathrm{He} / \mathrm{O}_{2}$ in seven patients whose chronic bronchitis and emphysema were of similar severity to that of the patients in this study. We found that the mean nitrogen concentration in the ultimate forced expiration was $31 \%$ (range $28-41 \%$ ) and thus even in the case of the worst washout of nitrogen there was a $35 \%$ reduction in the density of the exhaled gas. Therefore the small increase in expiratory flow rates we observed in the present study cannot be explained by inadequate replacement of air by $\mathrm{He}$ /
$\mathrm{O}_{2}$ implying that most of the resistance to airflow on forced expiration in our patients with severe chronic bronchitis lay in their small airways, where gas viscosity determines the pressure/flow relationships.

The change in flow on breathing $\mathrm{He} / \mathrm{O}_{2}$ before ipratropium was significantly correlated to that breathing $\mathrm{He} / \mathrm{O}_{2}$ after ipratropium $(\mathrm{r}=0.48$, $P<0.05)$ but there was a wide degree of variation in some individuals (fig 4). Ipratropium had no significant effect on the change in $\mathbf{V} \max _{50}$ breathing $\mathrm{He} / \mathrm{O}_{2}$. As $\mathrm{V} \max _{50}$ is the flow rate when $50 \%$ of the VC has been exhaled into the spirometer, however, because of the increase in FVC (mean 0.51 ) after ipratropium, $V \max _{50}$ after ipratropium was measured at a different lung volume and thus a different lung recoil pressure than in the control period. It is therefore difficult to draw physiological conclusions by comparing $\mathrm{V} \max _{50}$ and the response to $\mathrm{He} / \mathrm{O}_{2}$ before and after ipratropium. In the six subjects studied in the plethysmograph, however, lung volumes were measured before performing forced expiratory manoeuvres and so flow rates can be compared at the same absolute lung volume $\left(50 \% \quad \mathrm{VC}_{\mathrm{VTG}}\right)$ and at the same lung recoil pressure. In these subjects $V \max _{50} \quad V_{\text {VTG }}$ rose by $79 \% \quad(P<0.001)$ after ipratropium, but there was no change in the percentage response to $\mathrm{He} / \mathrm{O}_{2}$ before $(10 \%$ SD $12 \%)$ as compared with after ipratropium (15\% SD $14 \% ; P>0.5$ ). In fact there was no difference between the percentage response to $\mathrm{He} / \mathrm{O}_{2}$ measured at $50 \%$ VC $_{\text {VTG }}$ after ipratropium (15\% SD $\left.14 \%\right)$ and the percentage response to $\mathrm{He} / \mathrm{O}_{2}$ measured at $50 \% V_{\text {Cexhaled }}(18 \%$ SD $32 \% ; \mathrm{P}>0.7)$. Extrapolating this to the unaltered response to $\mathrm{He} / \mathrm{O}_{2}$ in $\mathbf{V} \max _{50 \text { exhaled }}$ after ipratropium in all 21 patients we suggest that the distribution of resistance to expiratory flow was not altered by ipratropium and that expiratory flow was still limited by the small airways in these severe chronic bronchitics. This is in agreement with results in normal subjects, in whom ipratropium appears to dilate both large and small airways (Douglas et al, 1976).

There was no correlation between the change in flow rates on breathing $\mathrm{He} / \mathrm{O}_{2}$ and the increase in $\mathrm{FEV}_{1}$ produced either by ipratropium $(\mathrm{r}=0.06)$ or by salbutamol $(r=0.37, \mathrm{P}>0.1)$. This contrasts with suggestions based on a small group of patients that in asthma, patients with severe airways obstruction who have a poor response to $\mathrm{He} / \mathrm{O}_{2}$ do not subsequently improve whereas those who increase their $V \max _{50}$ by greater than $20 \%$ on breathing $\mathrm{He} / \mathrm{O}_{2}$ will respond to treatment (Benatar et al, 1975). Indeed, there was no cor- 
relation between the percentage response to $\mathrm{He} /$ $\mathrm{O}_{2}$ in the control period on two days of the studies $(r=0 \cdot 12)$, even in our very stable group of patients. We therefore feel that measuring the response of an individual bronchitic to $\mathrm{He} / \mathrm{O}_{2}$ is of no predictive value.

We thank Boehringer Ingelheim for their financial support and also for their supplies of ipratropium and placebo aerosols.

\section{References}

Altounyan, R E C (1964). Variation of drug action on airway obstruction in man. Thorax, 19, 406-415.

Baronti, A, and Grieco, A (1976). A comparative trial of bronchodilator effects of fenoterol and $\mathrm{SCH}$ 1000 in chronic bronchitis. Bulletin Européen Physiopathologie Respiratoire, 12, 533-543.

Benatar, S R, Clark, T J H, and Cochrane, G M (1975). Clinical relevance of the flow rate response to low density gas breathing in asthmatics. American Review of Respiratory Disease, 111, 126-134.

Cabezas, G A, Graf, P D, and Nadel, J A (1971). Sympathetic versus parasympathetic nervous regulation of airways in dogs. Journal of Applied Physiology, 31, 651-655.

Christie, T (1811). Account of the good effects from inhaling the smoke of several species of Datura, especially the Datura Fastuosa, in Asthma. Edinburgh Medical and Surgical Journal, 7, 158-160.

Despas, P J, Leroux, M, and Macklem, P T (1972). Site of airway obstruction in asthma as determined by measuring maximal expiratory flow breathing air and a helium-oxygen mixture. Journal of Clinical Investigation, 51, 3235-3243.

Douglas, N J, Sudlow, M F, and Flenley, D C (1976). The effect of an inhaled atropine-like drug on airway function in normal subjects. Journal of Applied Physiology. In press.

Engel, L A, Landau, L, Taussig, L, Martin, R R, and Sybrecht, G (1976). Influence of bronchomotor tone on regional ventilation distribution at residual volume. Journal of Applied Physiology, 40, 411416.

Herxheimer, $H$ (1959). Atropine cigarettes in asthma and emphysema. British Medical Journal, 2, 167171.

Hossain, S, and Heard, B E (1970). Hyperplasia of bronchial muscle in chronic bronchitis. Journal of
Pathology, 101, 171-184.

Kanbour, A, Douglas, N J, Sudlow, M F, and Flenley, D C (1977). The relative distribution of airflow resistance in normal subjects and patients with airway obstruction. Clinical Science and Molecular Medicine, 52, 27P.

Medical Research Council (1965). Definition and classification of chronic bronchitis. Lancet, 1, 775-779.

Palmer, K N V, and Diament, M L (1969). Dynamic and static lung volumes and blood-gas tensions in bronchial asthma. Lancet, 1, 591-593.

Pedley, T J, Schroter, R C, and Sudlow, M F (1970). The prediction of pressure drop and variation of resistance within the human bronchial airways. Respiration Physiology, 9, 387-405.

Petrie, G R, and Palmer, K N V (1975). Comparison of aerosol ipratropium bromide and salbutamol in chronic bronchitis and asthma. British Medical Journal, 1, 430-432.

Poppius, H, and Salorinne, Y (1973). Comparative trial of a new anticholinergic bronchodilator, SCH 1000 , and salbutamol in chronic bronchitis. British Medical Journal, 4, 134-136.

Postgraduate Medical Journal (1975). The place of parasympatholytic drugs in the management of chronic obstructive airways disease. 51, suppl 7 .

Stanescu, D C, de Sutter, P, and Woestijne, K P van de (1972). Pressure-corrected flow body plethysmograph. American Review of Respiratory Disease, 105, 304-305.

Storms, W W, Do Pico, G A, and Reed, C E (1975). Aerosol SCH 1000. American Review of Respiratory Disease, 111, 419-422.

Thurlbeck, W M, Henderson, J A, Fraser, R G, and Bates, D V (1970). Chronic obstructive lung disease. Medicine, 49, 81-145.

Weibel, E R (1963). Morphometry of the Human Lung. Academic Press, New York.

Wellman, J J, McFadden, E R, and Ingram, $\mathbf{R} H$ (1976). Density-dependence of maximal expiratory flow rates before and after bronchodilators in patients with obstructive airways disease. Clinical Science and Molecular Medicine, 51, 133-139.

Yu, D Y C, Galant, S P, and Gold, W M (1972). Inhibition of antigen-induced bronchoconstriction by atropine in asthmatic patients. Journal of $A p$ plied Physiology, 32, 823-828.

Requests for reprints to: $\operatorname{Dr} \mathrm{N} J$ Douglas, Department of Medicine, The Royal Infirmary, Edinburgh EH3 9YW. 